\title{
STREET SPACE FROM THE VIEW OF HUMAN INTERACTION Kristián Čulík ${ }^{1}$, Alica Kalašová ${ }^{2}$, Zuzana Otahálová $^{3}$
}

\begin{abstract}
The dramatic increase in automobile transport over the last few decades has often led to the degradation of a basic element of the urban space - streets, the essential part of every urban area - to simple transport corridors. Life in the street is a dramatic stage on which we all are participating actors. The meaning of streets goes beyond the fact that they lead somewhere else and thus hold the city together, but the streetscape has a meaning in and of itself - we are out in the street because we want to be there. Like other components of the urban space, streets have a spatial dimension but, perhaps uniquely, also have their temporal element. In my contribution I would like to characterize a street in a town and its role in the modern way of life. Streets and public spaces are important elements that make up a city. The rapid increase of number of vehicles brought changes in the character and function of the street space. The streets were perceived primarily as a space reserved for transport, to the detriment of its residential, social and aesthetic function. Vehicles in motion and mainly parked cars gradually occupied a larger part of public areas and they do not allow other activities.
\end{abstract}

UDC Classification: 656, DOI: 10.12955/cbup.v7.1391

Keywords: traffic, calming, street, environment

\section{Introduction}

The rapid increase in road traffic over the past few decades has often led to the degradation of the basic type of public space - a street. It is an important part of every city and it is usually degraded to simple traffic corridor. "Living between buildings has a wide range of activities that gives a sense and appeal to public spaces of the city..." says Gehl (2000). The street connects parts of the city, but it has also other significance. We are on the street because we want to be on it. The street is a space and, unlike other static elements of the city, the time dimension is the most important existential symbol of the city.

Streets and public spaces are important elements that make up a city. The rapid increase in number of vehicles brought changes in the character and function of the street space. The streets were perceived primarily as a space reserved for transport, to the detriment of its residential, social and aesthetic function. Vehicles in motion and mainly parked cars gradually occupied a larger part of public areas and they do not allow other activities.

That is why people spend more and more time at home. Children have lost the opportunity to play outdoors in the street because there are safety reasons for young children. This represents a serious impact to their physical and mental development. With the loss of attractiveness of busy streets, the attractiveness of the shops and shopping in the centre is reduced. At the same time, more and more business activities are moving to suburban shopping centres, accessible only by car. As a result, the demands of car traffic are increasing (Culik, 2017).

Mobility is a normal part of our lives. Whoever wants to be mobile needs always some kind of vehicle. From the psychological-sociological point of view it is defined as "need for change of place", and "traffic" is defined as a means of achieving it. We can say that mobility and transport are one. This implies that realizing mobility that meets real needs, with the least possible use of transport, is a base for sustainable development for the saving of the environment for future generations (Kalasova and Surovec, 2008).

The basic criteria for the quality of development of individual modes of transport include its safety. The most vulnerable transport participants are unprotected categories of road users - pedestrians and cyclists.

\section{History of Street Traffic Calming}

In the Middle Ages the street had a social function. Originally a street space formed part of adjacent buildings and served as an access road for pedestrians, coaches and carts. The craft and merchant operations occupied part of the street area. Residents sat in front of the houses, and the street served for

\footnotetext{
${ }^{1}$ Faculty of Operation and Economics of Transport and Communications, University of Žilina, Žilina, Slovakia, kristian.culik@fpedas.uniza.sk

${ }^{2}$ Faculty of Operation and Economics of Transport and Communications, University of Žilina, Žilina, Slovakia, alica.kalasova@fpedas.uniza.sk

${ }^{3}$ Faculty of Operation and Economics of Transport and Communications, University of Žilina, Žilina, Slovakia, zuzana.otahalova@gmail.com
} 
everyday people-to-people contacts. People's activities and contacts prevailed over traffic. The first type of the street is shown in the figure 1.

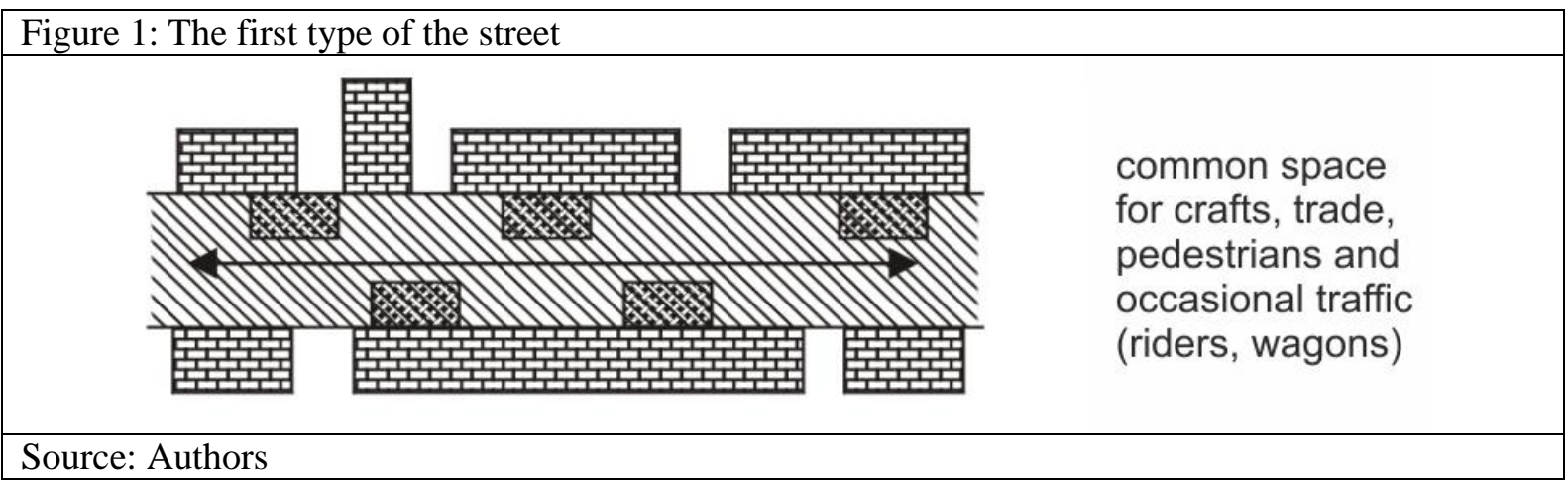

Later, the traffic importance of the street increased. Streets were used to access built-up areas and the increasingly intense traffic that passed through this area, grew. First, the carriage by horse, later by the steam engine and electricity, the driven street track, and finally cars, pushed out pedestrians moving freely throughout the street. Shops and crafts moved into buildings and yards and started to build sidewalks. The street function slowly changed from social to traffic. The second type of the street is shown in the figure 2.

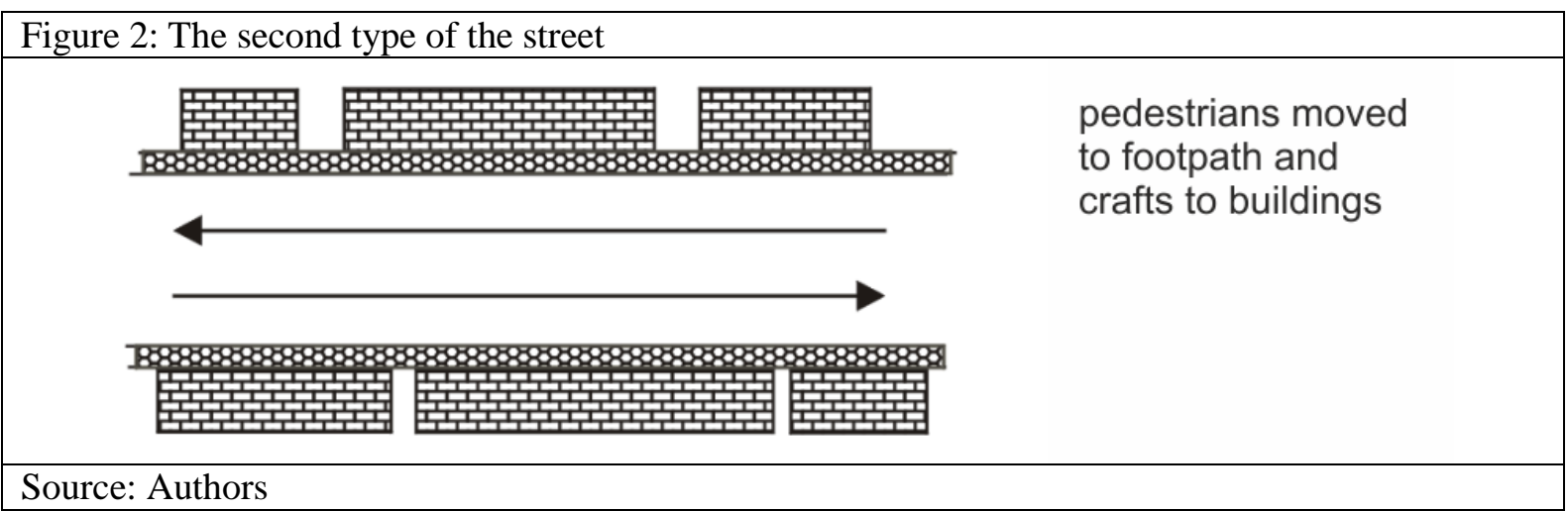

In the next period, the growing number of cars filled the streets not only while they were driving, but also during when they were parked along sidewalks. There was a need for regulatory interventions in transverse arrangement. The street has expanded; some streets have tracks for tramway traffic, traffic lanes, and special lanes for services, lanes for parking and pedestrian space along the buildings. In this way a corridor street was created and it is shown in Figure 3.

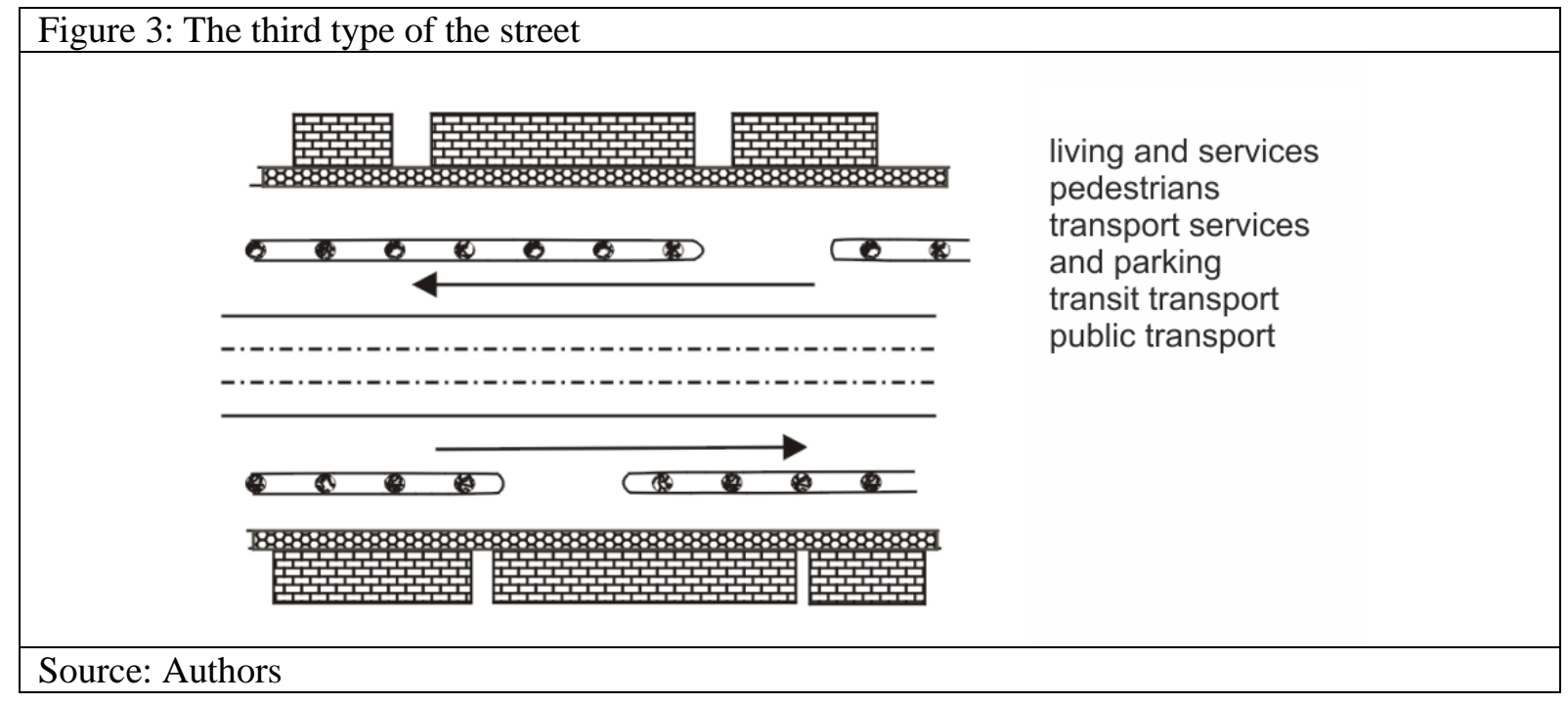


At present, buildings moved further away from the road and they make up an independent part. Transit traffic and public transport has reserved a separate area, usually with separated lanes by a green splitter island. The main pedestrian roads are moved to the greenery on the opposite side of the buildings. This is seen in Figure 4. There is an effort to give the residential area an atmosphere of the original urban environment with the possibility of peaceful contact between people, without noise, emissions and dangerous traffic (Poliak, 2013).

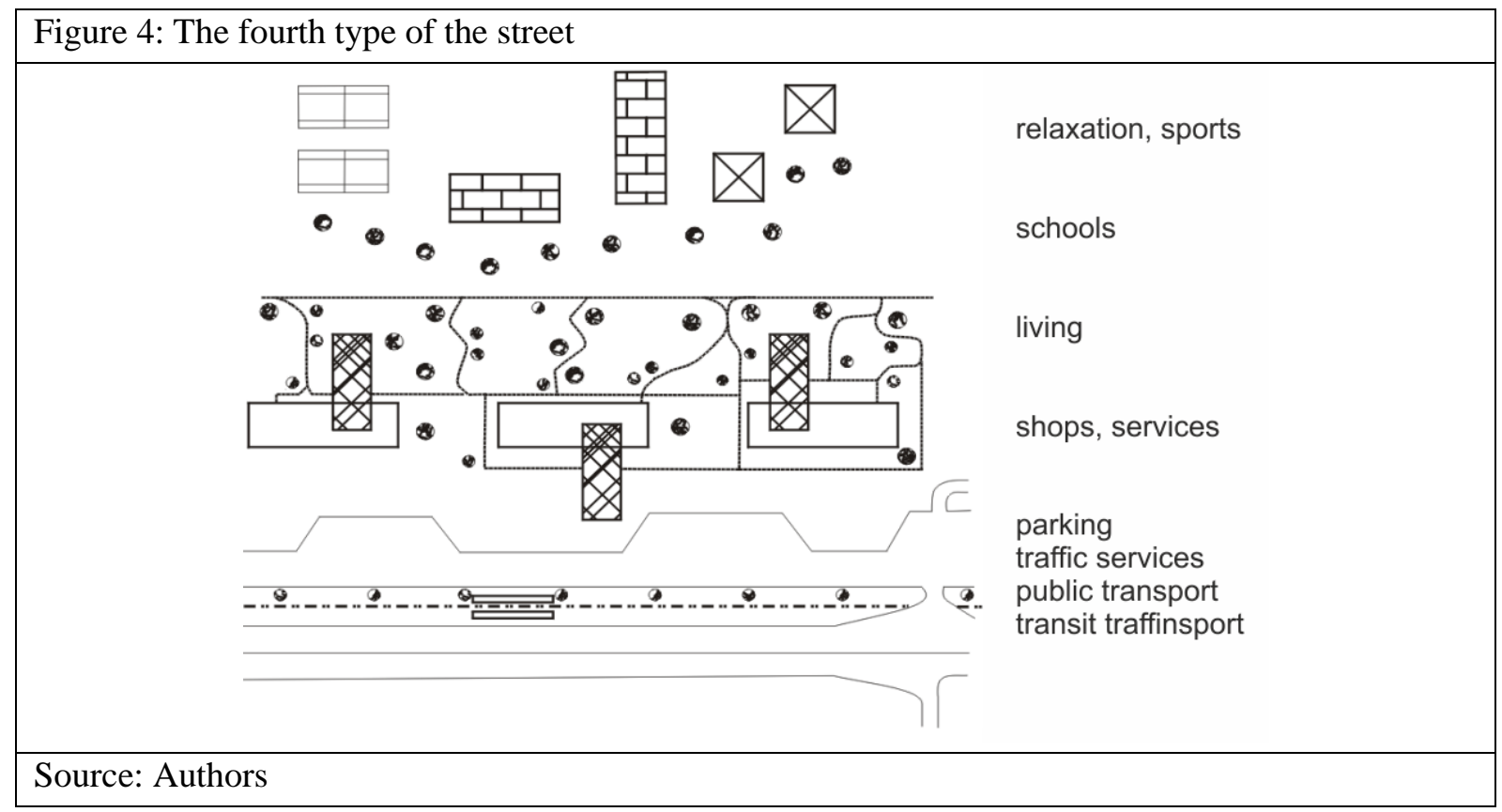

\section{Characteristics of The Street Space}

The street is a multifunctional space. Targeted and systematic efforts to rehabilitate the public space in Western Europe has been seen since the early 1970s. Their aim was to return the street to humans. Nevertheless, the quality of these spaces between buildings is often measured primarily by traffic characteristics. The street has five basic (primary) features depending on its function for the city:

- living function (residential, commercial, social),

- service (target transport - supply, pedestrian access, bus stops, parking) and transport function (transit transport - individual, public, freight transport, cycling and pedestrian traffic),

- engineering networks (sewerage, water supply, gas pipeline, hot water, power lines, telecommunications),

- city-forming function (arrangement of area, size and shape of building blocks, street network, city composition).

The basic functions realised in the street have their own requirements for the environment. Sometimes they influence the environment themselves, so they have requirements for their effects on the urban structure. Noise and exhausts have a very negative impact on the city. For example dividing the city centre with a wide barrier for important road communication is undesirable for the city. On the other hand, successfully ensuring the living, transport of goods and transport services require a wide range of actions. The street meets the demands of pedestrian safety, street facilities and equipment and aesthetics and mental well-being (Ondrus and Kolla, 2017).

Especially the living function has high demand on the subjective evaluation of the public space by an individual man who is living or staying there. Man relies on his senses, especially sight, hearing and smell.

The first step to grab some part of the city is its name. It is the first symbol of the specific meaning of a particular place. It combines the present with the past, is part of the address and thus home. The street must be clearly structured in the space - its relationship with the environment must be defined, as well as the relationship between the elements. Therefore, the street must be delimited, clear, predictable, comprehensible, legible, meaningful, and different than others. The illogical and non-systemic position in the city is disorienting. Excessive size and formlessness of the street are associated with a sense of 
hopelessness and eradication. The overall impression is based on the harmony of all its parts. The street is more acceptable by people, not only if they can see from one side to the other, but also if they are able to walk without difficulty. Small spaces allow contact and feel intimate.

The development and functioning of public urban spaces is beyond the normal economic rules of the city's functions. It is connected with the performing of sub-investment actions. Both the city and the street are a synthetic organism, developed as a response to the specific needs of the time. They are developed because it is worth it. Streets not only lead somewhere, but also access and serve the surrounding buildings. In a traditional European city, it is unthinkable for a street to exist on its own, without a functioning urbanized area, without prosperous buildings that actually create it. People who live or work on or go along a specific street create demand for a variety of civic amenities and services. Then it reinforces other services or jobs and some forms of housing. A diverse range of functions is a basic assumption for the attractiveness and function of a standard street as we know it in our cities for many generations.

The attractiveness of streets in residential areas is connected with the ability to eject a part of the living activities into the street space. Then the street is the place to meet the inhabitants of the living community, the children's play area and sometimes the place for parking of cars. Children usually do not look for playgrounds behind the house or somewhere outside the park, but they love life most on the street, which gives them a lot of opportunities for their development. A great opportunity to engage in street activities is creating private front yards. There the residents can not only work, but also beautify their little land. It is also a place for doing housework. From this point of view, it seems more beneficial to build a street as a non-contact solitaire in the middle of fenced gardens (Kalasova et al., 2016).

According to Ondrus and Karon (2017), a man as a social creature does not go to shops just to buy, he does not go to restaurants, wine bars and cafes just to eat or drink. Similarly, walking down the street may not only have a material purpose. When someone is starting to do something, it is a clear challenge for others to join either by direct participation or by watching what others are doing... people are attracting more people.

Reasons, why people visit the street are:

- they want to pass the street for some other goal,

- they want to visit a facility located on that street,

- they are just on a walk and lost in an anonymous environment,

- they go on to meet someone, buy something or stop somewhere,

- they have met some person and now they are going somewhere,

One of the basic social requirements is to ensure security. Street safety is felt by people when:

- they do not feel lost in the chaos and confusion of strange environment,

- they are not at risk of crime,

- they avoid collisions with vehicles.

The street is one of the basic elements of spatial arrangement. Streets make and organize territories. They allow quick movement and finding the right object, so the city becomes more "readable", understandable and also safe. Identifying and living with the surrounding environment is essential for mental balance, home and happiness. People are usually afraid of staying in public spaces like train and bus stations, especially at night. In general, the empty, narrow streets in industrial and uninhabited areas are also considered as less secure.

For the aesthetics of the city, the anti-renaissance tradition based on Aristotle's teachings undoubtedly had great significance in history, according to which beautiful harmony, proportionality, scale, harmony and the like are essential. The criterion for the aesthetics is then the measure, the beautiful thing must not be too small or too big, it must describe the nature of the particular kind. The house must look as much as a house, the beautiful street is the one that most resembles a traditional street. From this point of view, it is possible to define the ideal of beauty as the rules by which the desired result is achieved.

\section{Street Traffic Calming}

The beginnings of limiting car traffic are related to the report "Traffic in Towns: A Study of Long Term Problems of Traffic in Urban Areas" (Department of Transport, 1963), where it was officially stated 
that traffic growth is worsening the quality of life in cities. The author of this report, Colin Buchanan is considered as the "father" of traffic calming.

Firstly, the effort was to adjust the street network with blocking, one ways and other interventions to make these streets less attractive for transit traffic. These programs were called "environmental transport management". The relocation of transit traffic does not eliminate some problems, especially accidents. Hence the emphasis has been shifted from trying to change the nature and shape of the road network towards modifying the behaviour of road users, especially drivers.

The first impulse, which meant the beginning of traffic calming, was the formation of "Woonerf" (traffic calmed streets in residential areas) and "Winkelerf" (traffic calmed zones in commercial areas) in the Netherlands. The first Woonerf (or places for life) were established in the late 1960s in the Dutch town of Delft. There citizens initiated a change, because the traffic situation was unbearable. Streets were used mainly for transit traffic and hence they changed them to places where there were benches, greens, sandboxes and parking bays. Support for Woonerf implementation was officially expressed by the Dutch government in 1976. The principle of Woonerf creation spread very quickly in Denmark, Germany, Sweden, the UK, France, Japan, Israel, Austria and Switzerland. However, building a Woonerf was not a solution for all problematic streets. Woonerf was only suitable for streets with low traffic. The construction of traffic calming elements made the reconstruction of streets more expensive up to 50\%. Also, the speed of the traffic has dropped on modified streets almost to the speed of walking. It was only acceptable for short distances. The Dutch were trying to find out if the principles used in the construction of the Woonerf are applicable at lower costs and for other categories of roads. For this purpose, the advantages of using the Woonerf elements were compared with two other options. The first was traffic reducing with entry bans and one way streets. The second compared options were application of standard traffic calming physical elements like speed bumps, elevated road sections, splitter islands, etc. (Kalasova et al., 2016).

The implementation of these measures was officially supported by the Dutch government in 1983. In Denmark, "stille veje" (silent streets) started to be used. The new "Tempo 30" zones grew in Germany and 20mph zones in the UK.

\section{Conclusion}

Traffic calming in cities is a process that reflects the endeavour to enhance a new quality of life and the implementation of modern transport policy at the European level. In practice, it has many different forms depending on the type of territory and communication, as well as the requirements of specific citizens. It is great that after many years of hesitation, traffic calming is commonly used in the Slovak Republic. Promotion and public education and presentation of good examples are a common task, because many solutions are little known about. However, during the time it is necessary to support the European efforts to humanize the transport system (Ondrus and Hockicko, 2015).

Experience shows that there is no single solution to reduce congestion. One solution is creating more attractive and safer alternatives than individual transport, for example cycling and walking. Citizens should be able to optimize their journeys on the basis of an effective link between the different modes of transport.

To increase the attractiveness and safety of walking and cycling, local and regional authorities should ensure that these modes of transport are fully integrated into the urban mobility. Attention should be focused to the development of adequate infrastructure. Cycling and walking can be supported by initiatives in cities, companies and schools (Kalasova et al., 2012).

Street quality is a public and also a political matter. Nine tenths of our country's population live in large and small cities. The city is an environment where millions of people spend all their time, live, work and relax. In cities, a continuous process of improving the living and working environment can be seen: sunny, efficiently arranged, better equipped and comfortable apartments, clean offices and healthier schools, hospitals and factories. All these elements have positive impact on improving the individual's life. Therefore, there is no reason for the spaces outside the buildings to be ignored from this logical trend. Sometimes they are deteriorated only because public spaces are not private and nobody cares about them. 
The streets in our towns and cities should not be only roads of standard types A, B, or C, which are used only for means of transport and walking people. It should be a place for living and spending free time as Capek says (1980).

\section{Acknowledgement}

This work was supported in part by the Grant VEGA no. 1/0436/18 - Externalities in road transport, an origin, causes and economic impacts of transport measures.

\section{References}

Capek, K. (1980) : London Street. Travel sketch of English letter. Writings of Karel Čapek. Travel.

Gehl, J. (2000) Life between buildings. Brno: Nadace Partnerství., Gehl. 202 s. ISBN 80-85834-79-0.

Kalasova, A. and Surovec, P. (2008). Calm traffic. EDIS - vydavatel'stvo ŽU Žilina - 202 s., 152 obr., 4 tab, AH 14,73, VH 15,26. - ISBN 978-80-8070-792-7

Poliak, M. (2013). The Relationship with Reasonable Profit and Risk in Public Passenger Transport in the Slovakia. Ekonomicky Casopis, 61(2), 206-220.

Ondrus, J. and Hockicko, P. (2015). Braking Deceleration Measurement Using the Video Analysis Of Motions by SW Tracker. Transport and Telecommunication Journal, 16(2), 127-137.

Culik, K. et al. (2017). Simulation as an Instrument for Research of Driver-vehicle Interaction. I O. Stopka (Red.), 18th International Scientific Conference-Logi 2017 (bd. 134). Cedex A: E D P Sciences.

Kalasova, A. et al. (2012). A New Approach to Road Safety in Slovakia. Telematics in the Transport Environment, $329,388$. Kalasova, A. et al. (2016). The Impact of Intelligent Transport Systems on an Accident Rate of the Chosen Part of Road Communication Network in the Slovak Republic. I J. Mikulski (Red.), Challenge of Transport Telematics, Tst 2016 (bd. 640 , s. 47-58). Cham: Springer Int Publishing Ag.

Ondrus, J. and Karon, G. (2017). Video System as a Psychological Aspect of Traffic Safety Increase. In J. Mikulski (Ed.), Smart Solutions in Today's Transport (Vol. 715, pp. 167-177).

Ondrus, J. and Kolla, E. (2017). Practical Use of the Braking Attributes Measurements Results. In O. Stopka (Ed.), 18th International Scientific Conference-Logi 2017 (Vol. 134). 